\title{
Studying the Moisture Flux over South and Southwest of Iran: A Case Study from December 10 to 13, 1995 Rain Storm
}

\author{
Ahmad Roshani ${ }^{1}$, Fateme Parak ${ }^{1}$, Zahra Hejazizade ${ }^{1} \&$ Hooshang Ghaemi $^{1}$ \\ ${ }^{1}$ Department of Climatology, Tarbiyat Moallem University, Tehran, Iran \\ Correspondence: Ahmad Roshani, Department of Climatology, Tarbiyat Moallem University, Tehran, Mofatteh st, \\ Iran. Tel: 98-919-319-4730. E-mail: ahmadroushani@yahoo.com
}

Received: November 22, 2012 Accepted: December 21, 2012 Online Published: February 20, 2013

doi:10.5539/esr.v2n2p34

URL: http://dx.doi.org/10.5539/esr.v2n2p34

\begin{abstract}
During December 10-13, 1995 a destructive flood occurred over the south part of Iran resulting from the intensive rainfall causing the social and economical damages over that area. This study intends to reveal the main moisture source flux which feeds in the rain fall weather system. The precipitation amount over the study area is four times greater than normal mean in December. The relationships between local atmospheric circulation and moisture flux divergence is investigated for this case of rainfall over south of Iran. The data used in these study includes rainfall data, from data processing center of IRIMO (Iran meteorological organization) and reanalysis daily data at every six hours interval for the same period and eight levels of NCEP-NCAR, with resolution 2.5 degrees in 0-80 $\mathrm{E}$ and 10-60 $\mathrm{N}$ domain. The high pressure circulation over the North East of Arabian peninsula at surface to $700 \mathrm{hPa}$ coupled with trough over the East of Mediterranean and west of the Red sea, transfer sufficient moisture in low levels of the troposphere from west of Indian ocean (Oman and Arabian seas), Aden gulf and Red sea to the center and North of Arabia and south of Iran. The average of perceptible water content in all troposphere level $(1000-300 \mathrm{hPa})$ that comes from the above mentioned region to the South West and south of Iran is about $(6-8) \times 10^{-3} \mathrm{~kg} / \mathrm{m}^{2} \mathrm{~s}^{-1}$. The most divergence of moisture flux in the lower level is from the west of the Indian Ocean while the source of moisture in middle and higher levels are from Aden gulf and the Red sea.
\end{abstract}

Keywords: moisture flux, divergence, rain storm, south and southwest of Iran

\section{Introduction}

The atmospheric moisture budget plays an important role in the hydrology of this region. The aridity in the southwest and the south of Iran is due to subsidence scale caused by Hadley circulation and a location far from oceanic source of moisture. However, the moisture and other properties of atmospheric quantities are transferred by local circulation from other source to the given region. Many investigations have been carried out in this subject. The consideration of the precipitation and its source region of moisture flux over the south and southwest of Iran, during 1970-74 has shown that 23 percent of the total low pressure system which passed over this area is from southwest of the Red sea (Faraji, 1982). In the investigation of moisture flux over Iran carried out by Alijani (1995) noted that the Mediterranean Sea is the main source of moisture for precipitation over Iran. Smith et al. (2003) and Evan et al. (2003) have shown that the Persian Gulf and Caspian Sea are the main source of moisture for precipitation over Alborz and Zagros mountains. They have shown that subtropical jet current brings the warm and moist air from the South part of Saudi Arabia and Aden gulf to the Middleeast in the middle and higher troposphere (Dayan \& Abramski, 1983).

The Red sea inverted trough at the surface with regard to its amplitude, is the Major source transfers warm and moist air from the Aden gulf to the East and north of Arabian Peninsula and also the southwest and south of Iran (Alpert, 2001). The low pressure system formed at the southwest of the Red sea is associated with high potential acceptability of moisture and warm air due to its characteristics of dynamical and thermo dynamical pressure for heavy rainfall over the study area. Rurerde (2006) using specific humidity map and its extension from the Caspian Sea to the Northern part of Iran derived a value of moisture quantities from each source region of moisture to the precipitation over Iran. Ghasemi and Khalili (2008) found a link with the North Sea-Caspian pattern (NCP) and Western Mediterranean Oscillation (WeMO). Also, Raziei et al. (2011) reported that the spatial distribution of precipitation over Iran is largely governed by geographical position of both the 
mid-troposphere trough over the Middle East and the Arabian anticyclone. However, relatively few studies have focused on the influence of the Indian Ocean climate variability even though it is a source of moisture. The Indian Ocean Dipole (IOD; Saji et al., 1999) is a large-scale climate mode that seriously influences many nations around the Indian Ocean rim, as well as global climate system. The principal objective of the present research is to understand the characteristics of moisture flux from each region of moisture source and their contribution to the rain fall during the mentioned period.

\section{Method}

The NCEP-NCAR reanalysis daily datasets for four days from December 10 to 13,1995 is employed to study the daily moisture flux, its origin and its perceptible water content. This data has been widely used by many researchers over the last few years in tropical climate researches. The precipitation dataset is received from data processing center of Iran metrological organization, but other atmospheric quantities such as specific humidity, zonal and meridional wind speed components used by the NCEP-NCAR reanalysis data. Since this research is concerned about daily aspects of moisture transport, all levels of winds and specific humidity used the above reanalysis to cover the research. For studying daily moisture flux during four days of rainfall over the south and southwest of Iran, divergence moisture flux is computed by the following formula:

$$
H F D=-\left(\left(u \frac{\partial q}{\partial x}+v \frac{\partial q}{\partial y}\right)+\left(q \frac{\partial u}{\partial x}+q \frac{\partial v}{\partial y}\right)\right)
$$

In the above equation $(q)$ is specific humidity $(u)$ and $(v)$ are zonal and meridional wind speed components. Respectively, $\left(\frac{\partial}{\partial x}\right)$ and $\left(\frac{\partial}{\partial y}\right)$, show the variation of atmospheric quantities such as specific humidity, wind and so on. The above equation can be extended as follows:

$$
H F D_{i j}=-\left(u_{i j} \frac{q_{i+1}-q_{i-i}}{x_{i+1 j}-x_{i-1 j}}+v_{i j} \frac{q_{i j+1}-q_{i j-1}}{y_{i j+1}-y_{i j-1}}+q_{i j} \frac{u_{i+1 j}-u_{i-1 j}}{x_{i+1 j}-x_{i-1 j}}+q_{i j} \frac{v_{i j+1}-v_{j i-1}}{y_{i j+1}-y_{i j-1}}\right)
$$

$H F D$, is horizontal divergence of moisture flux which negative sign means convergence and positive divergence.

$$
Q_{w i}=1 / g \cdot \int_{p B}^{p t} V q \cdot d p
$$

Where $\left(Q_{w i}\right)$, is the total moisture flux along the meridional in $\mathrm{kg} / \mathrm{m}^{2} \mathrm{~s}^{-1}$. Regarding the variation of local circulation and moisture content in each level and this region, it is better to compute the moisture flux in three individual levels $1000-700 \mathrm{hPa}, 700-500 \mathrm{hPa}$ and $500-300 \mathrm{hPa}$, as well as all troposphere levels $(1000-300 \mathrm{hPa}$, using the following equations:

$$
\begin{aligned}
& Q_{\text {low }}=1 / g \cdot \int_{1000}^{700} V q \cdot d p \\
& Q_{\text {mid }}=1 / g \cdot \int_{700}^{500} V q \cdot d p \\
& Q_{\text {top }}=1 / g \cdot \int_{500}^{300} V q \cdot d p \\
& Q_{\text {lclu }}=1 / g \cdot \int_{1000}^{300} V q \cdot d p
\end{aligned}
$$

It should be noted that the below equation was used for total vertical, horizontal divergence of moisture flux during rainfall period.

$$
Q_{v i}=\int_{P B}^{P t}\left(1 / g \cdot \int_{P B}^{P t} V q \cdot d p\right) \cdot d t
$$


The precipitation data was taken from 30 historical data synoptic; climatology and rain gauge stations including the south and southwest of Iran.

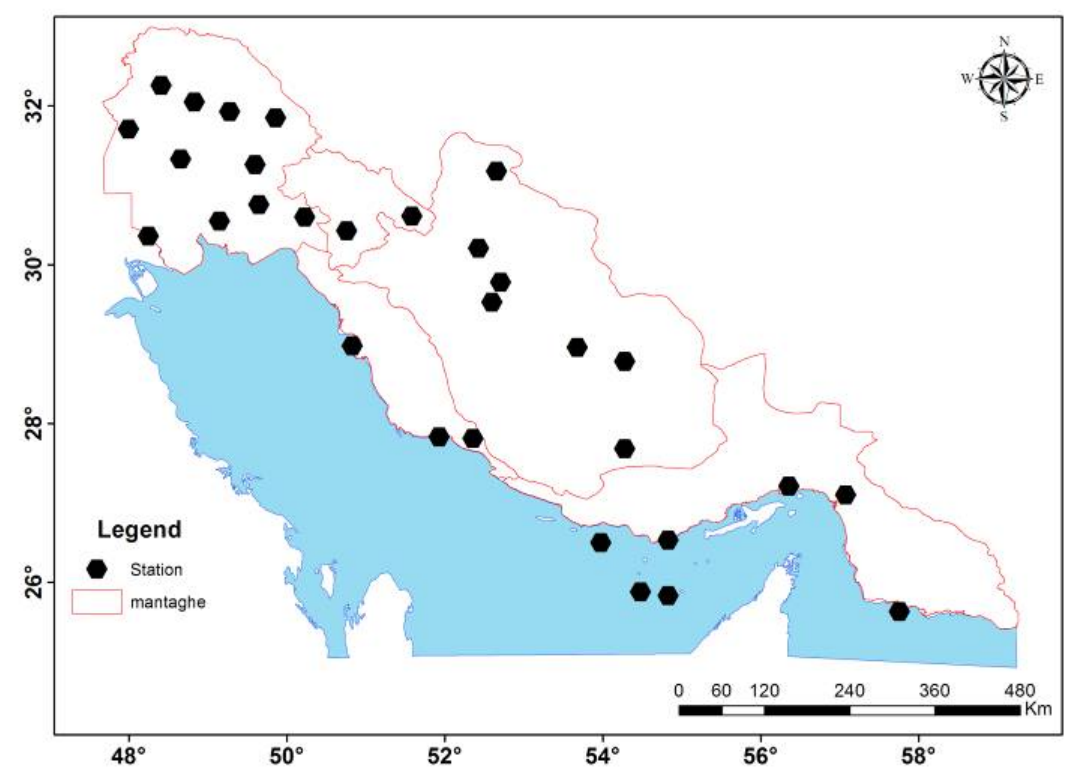

Figure 1. Spatial distribution of the stations in south and southwest of Iran

\section{Results}

In order to get a complete picture of the spatial and temporal pattern of the distribution of two days (11-12), rainfalls over the study area are presented in Figures $3 a$ and $b$. These figures show widespread rainfall greater than $10 \mathrm{~mm}$, but rainfall peak was observed during these two days over the East of the region. Figures $2 \mathrm{a}$ and $\mathrm{b}$ show the synoptic situation at 850 pha levels over the region for $11^{\text {th }}$ and $12^{\text {th }}$ at 00:00 UTC. These figures show the high pressure over Oman and Arabian seas and deep trough over the east Mediterranean and west of the Red sea.

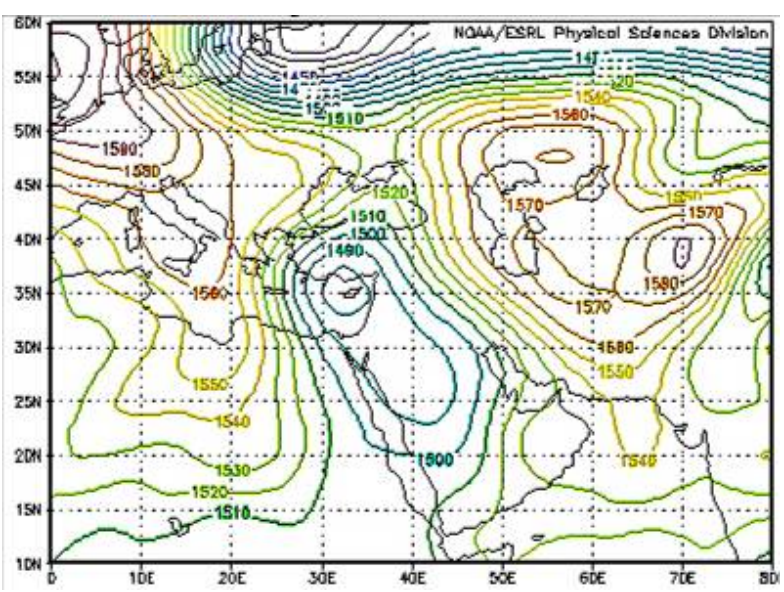

(a)

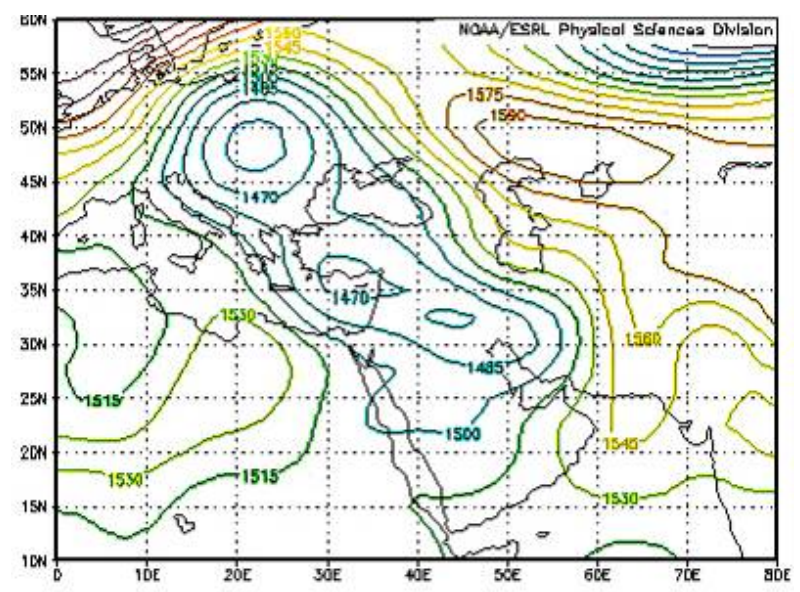

(b)

Figure 2. Geopotential height at $850 \mathrm{hPa}$ level in 00:00 hour a) December 11, 1995 and b) December 12, 1995 


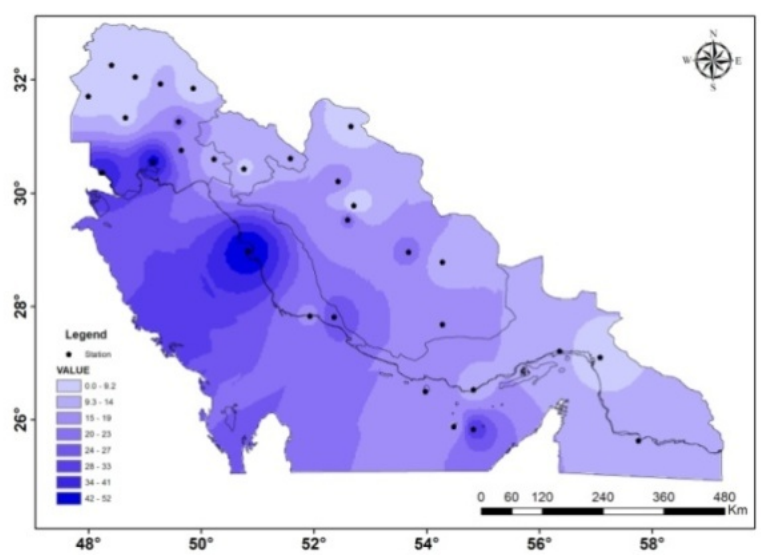

(a)

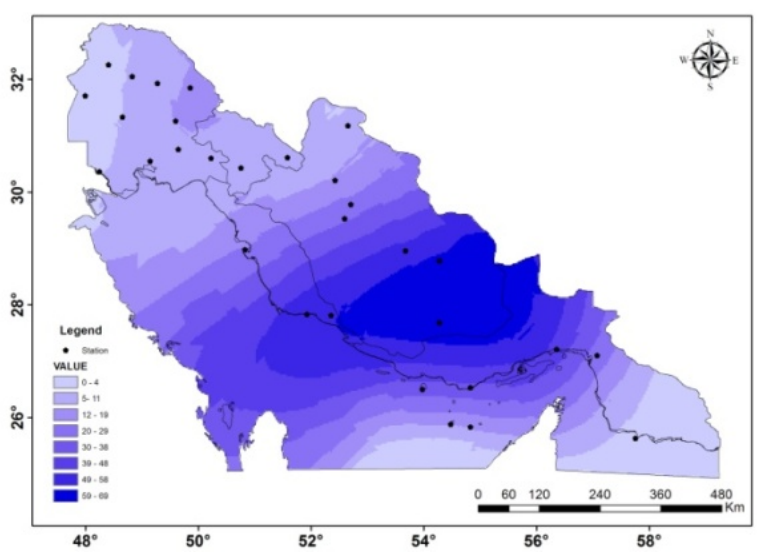

(b)

Figure 3. Daily precipitation map a) December 11, 1995 and b) December 12, 1995

\subsection{Moisture Flux and Perceptible Water Content}

The characteristics of moisture flux along with perceptible water content for different and all troposphere layers are presented in figures $4 \mathrm{a}$ and $\mathrm{b}$ and Figures $4 \mathrm{a}$ and $\mathrm{b}$. The divergent reflects the moisture source $(-) /$ sink $(+)$ region; the rotational describes the atmospheric water vapor transport. These components are described in data and methodology. In the lower troposphere, eastern Saudi Arabia received more perceptible water than the other part of the area during all two days of study (Figure 4a). Two moisture source regions as observed from the divergent flux, located over the Aden gulf and the Red sea, supply moisture to the study region. The south and south west of Iran receive precipitation water during this study, mainly from the west of Indian Ocean (Arabian Sea, Oman Sea and Aden gulf), the red sea and to some extent the Mediterranean. In the middle troposphere, divergent moisture flux reveal very important characteristics of rainfall over study region (Figure 4b). The divergent moisture flux during four days was observed over north part of Arabian Sea, Aden gulf, central of Red sea and convergence was observed over South, central of Arabian Peninsula, southwest and south of Iran. Moisture convergence in the lower troposphere and divergence in the middle troposphere during this study indicate the upward motion of moist air, which in turn may release latent heat due to condensation process. This available heat energy might be the source of low-level latent heat instability. The divergence moisture flux was observed during the same period over the same region. The large amount of perceptible water over Saudi Arabia in the middle troposphere is transported, by rotational wind from the Red sea and the Mediterranean as mention above. The upper troposphere distribution of the perceptible water content is low, during all 4 days, compared to that in the middle and lower troposphere. Thus upper-level moisture transport may not have much influence on precipitation over southwest and south of Iran.

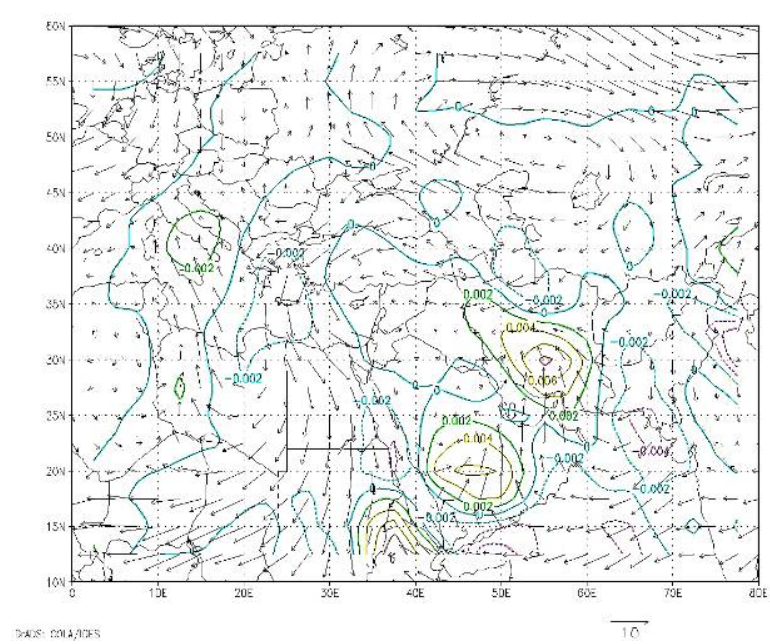

(a)

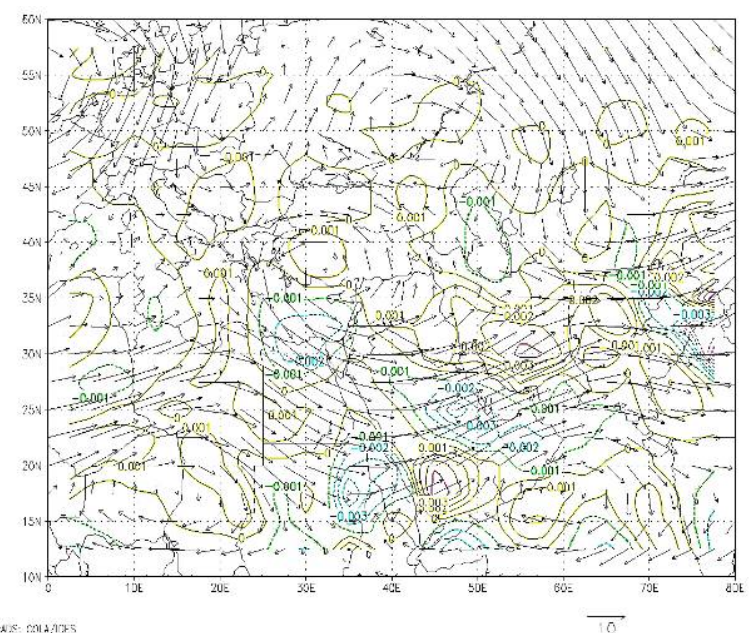

(b)

Figure 4. Divergence of moisture in the precipitation days a) lower layer; b) middle layer 


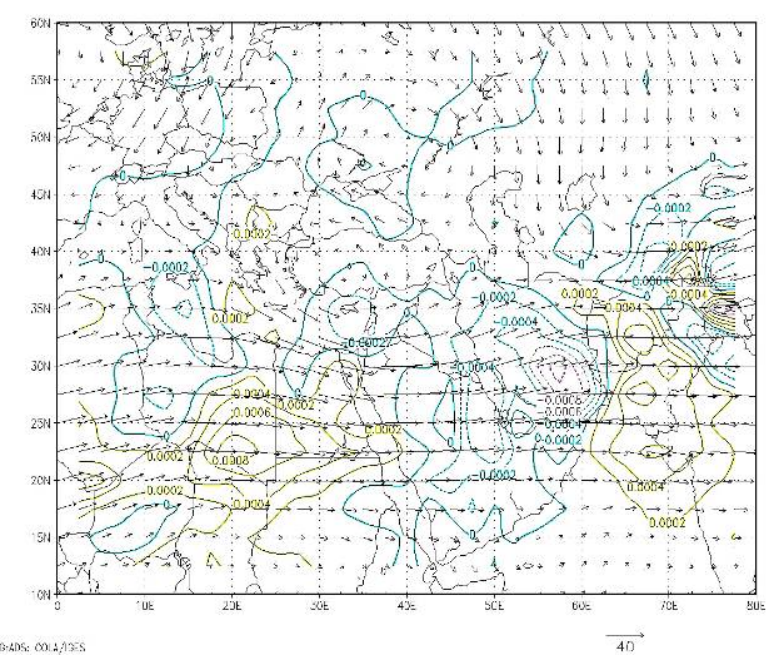

(a)

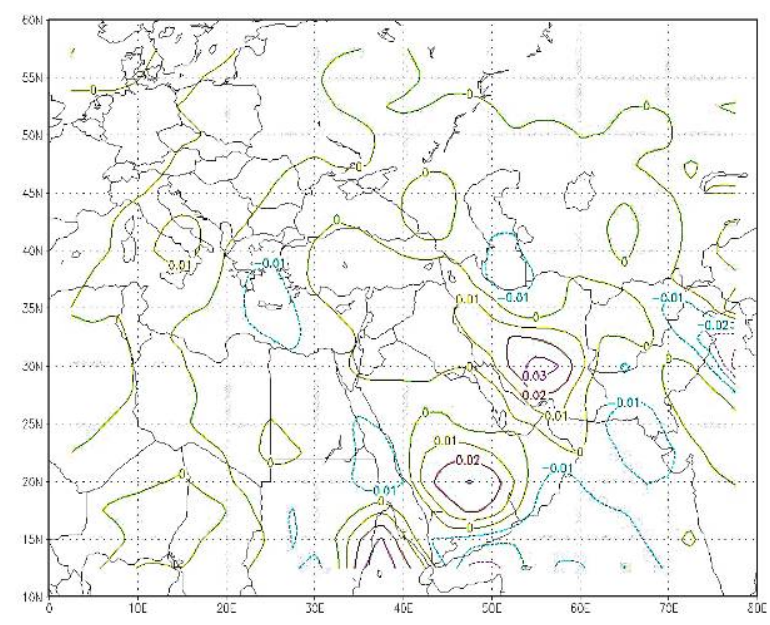

(b)

Figure 5. Divergence of moisture in the precipitation days a) upper layer; b) troposphere layer

\section{Discussion}

This study shows that due to deep trough of East Mediterranean and West of Red Sea, cold air transfer from southeast Europe to the Northeast of Africa resulting development of Sudan low. The low transfers to the center and the north of Arabian Peninsula then to the Southwest of Iran. The development of this low is due to release of sensible heat from the Arabian Desert and latent heat transferred from adjacent seas, to this area. This low affects southwest and South of Iran with significant value of perceptible water and low- level latent instability. The distribution of net in coming moisture flux during four days showed a peak in the second day of rainfall. It is seen that the transfer of moisture flux in the low-layer from Arabia Sea plays an important role in precipitation over the study region, but in the middle and higher layer of troposphere, moisture comes from the Red and Mediterranean seas. The findings of this study confirmed the results of the previous studies (Farajzadeh et al., 2007). They studied the rain storm over west part of Iran during 1-7 january 1996, they showed that this storm had produced widespread rainfall over the Western parts of Iran.this rain storm caused about $45 \mathrm{~mm}$ rainfall in $\mathrm{NW}, 117 \mathrm{~mm}$ in W and $100 \mathrm{~mm}$ in SW of Iran. Also they found that the main moisture source for the precipitation was the Arabian and Oman Seas at the lower level. At the middle level the Red Sea had more important role and the Mediterranean Sea is the source of the upper level moisture flux.

\section{References}

Alijani, B. (1995). The Sources of the moisture of precipitation of Iran. Proceeding of 7 th geographical congress of Iran March 10-13 1990. Tehran 2: 261-227. (In Persian).

Alpert, P., Neeman, B., \& Shay-E, Y. (1990). Intermonthly variability of Cyclone tracks in the Mediteranean. $J$. Climate, 3, 1474-1478. http://dx.doi.org/10.1175/1520-0442(1990)003<1474:IVOCTI>2.0.CO;2

Dayan, U., \& Abramski, R. (1983). Heavy Rain in the Middle east Related to unusual jet stream properties. Bull Amr Met Soc, 64, 1138-1140. http://dx.doi.org/10.1175/1520-0477(1983)064<1138:HRITME>2.0.CO;2

Dayan, U., Ziv, B., Margalit, A., Morin, E., \& Sharon, D. (2001). A severe autumn storm over the Middle east: synoptic and Mesoscale Convection analysis. Theo Appl Climatol, 69, 103-122. http://dx.doi.org/10.1007/s007040170038

Evan, J., Smith, R., \& Oglesby, R. (2003). Precipitation processes in the Middle East. Proceedings International Congress on Modeling and Simulation. MODISM03, Post, E. (Ed.). Townsville, Australia: Jupiter's Hotel and Casino.

Faraji, E. (1982). Evaluation of a low pressure system causing rain over Iran and provide a model of position and how they move. Thesis Meteorology, Geophysics Institute of Tehran University. (In Persian).

Farajzade, M., Karimi, A. M., Ghaemi, H., \& Mobasheri, M. R. (2007). Studying the moisture flux over west of Iran: A case study of January 1 to 7, 1996 rain storm. Journal of Applied Sciences, 7(20), 3023-3030 http://dx.doi.org/10.3923/jas.2007.3023.3030 
Ghasemi, A. R., \& Khalili, D. (2008). The association between regional and global atmospheric patterns and winter precipitation in Iran. Atmos Res, 88, 116-133. http://dx.doi.org/10.1016/j.atmosres.2007.10.009

Milind, M. (2006). Diagnostic analysis of wintertime rainfall events over the Arabian Region. Indian institute of tropical meteorology Research Report No RR-111.

Raziei, T., Mofidi, A., Satos, J. A., \& Bordi, I. (2011). Spatial pattern and regimes of daily precipitation in Iran relation to large-scale atmospheric circulation. Int. J. Climatol., 32(8), 1226-1237. http://dx.doi.org/10.1002/joc.2347

Rurerde, H. (2006). Determination moisture source of rainfall in South coast of the Caspian Sea. PhD Thesis, Tarbiat Moalem University, Tehran, Iran. (In Persian).

Saji, N. H., Goswami, B. N., Vinayachandran, P. N., \& Yamagata, T. (1999). A dipole mode in the tropical Indian Ocean. Nature, 401, 360-363 http://dx.doi.org/10.1038/43854

Smith, R. B., Evans, J., \& Oglesby, R. (2003). Mountain precipitation and hydrology in the Middle East. Int Conf Alpine Meteorol Brig Switzerland (pp. 19-23). 